\title{
Schema Theory and College English Reading Teaching
}

\author{
Xiaoguang Zhao ${ }^{1} \&$ Lei Zhu ${ }^{1}$ \\ ${ }^{1}$ School of Foreign Languages, University of Jinan, China \\ Correspondence: Lei Zhu, School of Foreign Languages, University of Jinan, Jinan, 250022, China. E-mail: \\ sfl_zhul@ujn.edu.cn
}

\author{
Received: August 6, 2012 Accepted: August 30, 2012 Online Published: September 12, 2012 \\ doi:10.5539/elt.v5n11p111 URL: http://dx.doi.org/10.5539/elt.v5n11p111
}

This research is funded by "The One Hundred Pioneer Courses for Reform of University of Jinan" (Program Number: "BMKC11028").

\begin{abstract}
Reading plays a dominant role among the four skills in foreign language acquisition for college students. Unfortunately, over the past few decades, English teaching practice shows that Chinese students are vulnerable in it. Both their reading speed and their reading skills are far from being satisfactory. Schema theory presents a very efficient course in developing students' reading skills and improving their reading abilities. Based on a descriptive research, this paper aims to expound on the schema theory, its activation and construction on college English reading class. The research shows that the application of the theory is fulfilled throughout the whole reading process by designing various activities before, during and after the reading. The results testifies the assumption that its application is beneficial to cultivate students' reading interest, quicken their reading speed and make proper judgments.
\end{abstract}

Keywords: Schema Theory, college English, reading

\section{Introduction}

Reading is one of the important skills in English learning. It is acknowledged that while in communication between input and output, language comprehension is the very important key link that we can't feel directly but it does exist (An, 2011).

However, the current situation of college English reading teaching is not promising. The traditional method fails to improve students' reading skills and increase their reading speed. Traditional teaching method is teacher-centered which makes students passive bystanders of the whole teaching process. The traditional way of teaching sees reading as a bottom-up process; in other words, the language hinder is the first thing students need to solve in the process of reading, and teachers are to help students solve this problem. It attaches so much importance to words and expressions that they are explained meticulously in great details before reading. However, the whole passage speaks more than its individual word or expression. Too much emphasis laid on parts tends to be an obstacle to the understanding of the whole. In addition, this way of teaching bores students and can not get them fully involved, let alone the development of their reading skills and speed. As a result, students can not read effectively, think independently, and develop their problem-solving abilities.

Schema was first mentioned by the Germany philosopher Kant in 1781. Today's schema derives from Gestalt psycholinguist F. Bartlett, who applied schema to psychology research. It is American artificial intelligence expert Rumelhart who finally developed schema into a systemic and integrated theory. And the educational psychologist Richard Anderson played an important part in introducing schema theory to the educational community. (Cui, 2002)

The theory interprets that when people comprehend, they need to combine their own background knowledge with the information in a text. In this process, the prior knowledge and knowledge structure works effectively in people's cognitive activities. All knowledge is packed into units, and these units are schema (Rumelhart, 1980). Since it involves individual experience, it succeeds in attracting students in reading and thus benefits them in raising their interest, increasing their reading speed, and making proper judgments in reading.

\section{Literature Review}

Today students slant to be passive and reluctant in reading. However, reading is an active and dynamic 
psychological process rather than a passive and mechanical one, which requires reader utilizes what he has learned to process the reading materials.

\subsection{Nature of Reading Comprehension}

Theorists vary on the nature of reading. Traditional opinions regards reading as a passive (bottom-up) decoding process. Thus it is believed that "meaning is embodied in the text and the reader can extract the meaning from the print if he understands it letter by letter and word by word" (Goodman, 1988). At the same time, reading is considered "primarily as a decoding process of reconstructing the author's intended meaning via recognizing printed letters and words, and building up a meaning for a text from the smallest textual units at the 'bottom' (letters and words) to larger and larger units at the 'top' (phrases, clauses, intersectional linkages)." (Goodman, 1988) This is the so-called bottom-up, or text-based view. Reading is a decoding process. Hence in teaching, teacher focuses on the analysis of words. Surely, it can help students memorize new words or phrases in reading, which lays a strong foundation for students' reading and learning English. However, this model makes students being much confined to the learning of the details.

Different from the above idea, a more popular concept is that "one's background knowledge plays a more important role than new words and new structures in reading comprehension" (Rumelhart, 1985). Therefore, "in teaching reading, the teacher should teach the background knowledge first so that students equipped with such knowledge will be about to guess meaning from the printed page" (Rumelhart, 1985). In this top-down model readers do not need to focus on every word, instead they make prediction on the meaning of the new words that they encounter. Obviously, here students' prior knowledge receives much importance since it produces the ability to predict meaning in reading process. Of course this top-down model requires corrections because it is often the case when reader is easily led to wild guessing and misunderstanding.

To better up these two ideas, it is reasonable to say that reading actually is an active process, or to be more exact, an interactive process. This more balanced view of reading posits a constant interaction between bottom-up and top-down processes, "each source of information contributing to a comprehensive reconstruction of meaning of the text" (Eskey, 1988). In other words, the interactive view considers the significance of both the print and the background knowledge in reading. It is said to be the "most applicable to reading instruction" (Heilman, 1990).

\subsection{Schema Theory}

Schema is a term used in psychology and cognitive science, which describes a systematic pattern of thought and behavior. Schemata affect attention and the absorption of new information. People use schemata to organize prior knowledge and provide a framework for future understanding.

\subsubsection{Definitions of Schema}

In 1781, Kant Immannel proposed the word "schema". He defined it as frame, script or background knowledge (Kramsch, 1993), which has long rooted in philosophy, psychology, and cognitive information process and so on. Cognitive psychologists used schema to explain the psychological process. British Gestalt psychologist, Sir Frederic Bartlett is regarded as the first person who used the term schema. He thinks that the term "schema" means an active organization of past reaction, or of past experience, which must always be supposed to be operating in any well-adopted organic response (Bartlett, 1932).

Carrell and Eisterhold wrote that language comprehension relied largely on the readers' background knowledge (Carrell, 1983). The text does not carry meaning itself, instead it provides directions as to what previously acquired knowledge is needed to extract meaning from the text. The previously acquired knowledge is called schema. Rumelhart and Ortony proposed that "schema represent stereotypes of concepts" (Rumelhart, 1977). Anderson and Pearson further explained that a schema is an abstract knowledge structure. It is abstract in the sense that it summarizes what is known about a variety of cases that differ in many particulars. It is structured in the sense that it represents the relationship among its component parts (Carrell, 1988).

\subsubsection{Three Types of Schema}

Schema can be classified into three types: linguistic schema, content schema and formal schema (Carrell, 1984).

Linguistic schema refers to readers' prior linguistic knowledge, including the knowledge about phonetics, grammar and vocabulary as traditionally recognized. Usually for Chinese students, the first problem is their limited vocabulary and syntactic knowledge. Eskey said that good readers know the language (Eskey \& Grabe, 1988). They should decode both the lexical units and syntactic structures they encounter in texts. Carrell and Eisterhold wrote that the second language readers should master certain linguistic knowledge to decode the text. Therefore, accumulated linguistic information is a necessity for readers to obtain when they want to decode 
meaning of a passage.

Content schema is the background knowledge an assay or the topic it relates to (Carrell, 1988). It involves many things, such as topic familiarity, cultural knowledge, conventions and previous experience of the domain. As culture-centered, this type of schema is, among the three, the very one which decides readers' understanding of a passage, since whatever kind of writing is read, it must be interpreted under a cultural context because it is a product of that culture. For students with low language proficiency, content schema is a very important tacky problem they should deal with.

Defined as "background knowledge about the formal, rhetorical, organizational structures of different kinds of texts" (Carrell, 1983), formal schema is "abstract, encoded, internalized, coherent patterns of meta-linguistic, discoursed, and textual organization that guide expectations in our attempts to understand a meaningful piece of language" (Carrell, 1983). It is the knowledge of different text genres and their respective structural organization, language structures, vocabulary, grammar etc. Argumentation, exposition, description and narration are the general types which are explained in writing books for students, but the fact is that the reading materials that they come across are of various subcategories under these four, such as newspaper reports, poems, short stories, editorials, and so forth. Their specific characteristics do work as a necessary part of the whole. To know them, readers find it easier to grasp the whole reading materials since it can help to deepen their understanding; otherwise, it becomes a hinder.

Schema enables readers to relate new information to their prior experience. By bridging the new with the old, unfamiliarity is decreased, interest is aroused, and prediction in reading is possible. Schema helps to solve the problems in reading and thus ensure to make the right decision.

\subsubsection{Functions of Schema in Reading}

As a cognitive framework which consists of a number of organized ideas, schemata usually are defined as abstract knowledge models or structures which may be of use in solving problems. It assumes that those knowledge models are stored in one's memory. And by the application of the stored knowledge structures, one can deal with a problem in reading quite easily.

In reading, drawing information from both the external graphic message and the internal schemata forms the comprehension of a message, which is immediately followed by the reconciliation of the two.as a single or new schema. Texts themselves, spoken or written, are the very key of schema theory. They provide listeners or readers clues to be utilized to form or generate new ideas. The process of comprehension is guided by the principle that every input is mapped against some existing schema and that all aspects of that schema must be compatible with the input information.

Comprehension is termed as an interactive process which works between the text and reader's background knowledge. Therefore, it always happens that readers contribute more information than the print on page. Readers understand what they read since during reading they tend to take the stimulus beyond its graphic representation and assign its membership to an appropriate group of concepts which are already stored in their memories. Reading skill depends on efficient interaction between them. The reading process, therefore, involves identification of genre, formal structure and topic, all of which activate schemata and allow readers to comprehend the text. Therefore, the schemata of various knowledge and experiences play a very important role in reading comprehension.

Schema theory presents a very efficient course in developing students' reading skills and improving their reading abilities required in current college English class.

\section{Related Study}

This study intends to find out whether teaching techniques based on schema theory can be applied feasibly and effectively in college English reading class. For this study, three questions are addressed.

1. What is the feedback of students when reforming the reading class?

2. How is the schema activated in reading comprehension?

3. How can teachers help students construct schemata when reading?

\subsection{Subjects}

All the subjects of this research are 100 students and 5 teachers from School of Foreign Languages, University of Jinan. Among the subjects, 21 are male students and 79 are female ones. They have studied English for 7 years, and their average age is 19.3. They are of approximately the same English proficiency according to their scores 
of the last-term final exam before the research. The family background, the study experience and the reading ability of the subjects are generally similar. And all the participants are chosen by random sampling.

\subsection{The Instruments and Design}

A survey is made through two questionnaires among 100 students subjects and 5 Chinese teachers of English in Jinan University. One of the questionnaires is designed for the students and the other is designed for the teachers. The students' questionnaire comprises seven questions and four open questions and the teachers' questionnaire contains ten open questions. All these serve as the principal means for gathering the necessary data for this paper. Among those questions on the students' questionnaire three questions concern the current situation of English reading class, and the rest are about students' attitudes or feeling towards the reform in the class. On the teachers' questionnaire the questions can be grouped into two sections. One section concerns the teachers' ideas toward their application of schema theory in class, while the other section is about their experience and feedbacks about the application.

\subsection{Data Collection}

There is a pilot study conducted before the real survey in order to secure the validity and reliability of the questionnaires. The pilot study is conducted among 10 students and 2 teachers. The researcher discusses with them after they have finished the questionnaires and makes some revisions. Then the revised questionnaires are delivered to the students randomly chosen from 5 classes and 5 teachers. There were 98 copies of the answered-questionnaires from the students are valid and all the 5 from the teachers are acceptable.

\subsection{Data Analysis}

A descriptive analysis of the data is conducted after the data were collected. The researcher computes the percentage of the answers in order to shed some light on the current condition of English Reading class, the participants' attitudes towards the use of the theory, and the changes the teachers have made on class.

\subsection{Results and Discussion}

The feedback of students' questionnaire shows that majority(79\%) of the students finds reading class without using schema theory is quite boring. $85 \%$ of them say that on class they are passive receiver of what the teacher says and they seldom think themselves. The percentage decrease from $79 \%$ to $34 \%$ on the class when the teachers employ the theory and innovate some activities on class. $63 \%$ of them say they participate more on reading classes since there are a growing number of activities provided by their teachers, which require individual or group efforts. The response from the teachers is also positive, and all of them find their classes are more active than before. And three of them says it becomes more difficult for them to control their classes. The findings of the study indicate that most of the respondents approve the extensive employment of various activities based on schema theory.

\section{Application of Schema Theory to English Reading Teaching}

\subsection{Schema's Construction}

First, construction of linguistic schema is introduced. Linguistic schema refers to the language knowledge, which is the fundamental of understanding a text and is an essential part in understanding passage background knowledge.

Vocabulary accumulation is one of difficult points for the college English learners. They always think memorizing words wastes a lot of time and are not efficient. The reason why this problem is caused is that they don't master a good method to memorize words. In the process of teaching words, teachers can combine the new words and words that have memorized, which can activate students' schema that was grasped. In the process of word teaching, the context where the word is in should be paid attention.

Grammar accumulation is also important. Grammar knowledge is an important part in reading. Teachers can explain the grammar that is encountered in teaching. This can also activate students' schema in mind.

Second, construction of content schema is introduced. Content schema is the background knowledge related to a reading passage. If readers lack the necessary cultural background knowledge, they still can't comprehend a text well although they master enough linguistic schemata. This is the reason why readers can understand words, phrases and sentences in a text, but they can't comprehend the text. Lacking enough cultural background knowledge, readers' linguistic schema can't make an interaction with the relevant content in the text. Hence, teachers can encourage students to read books or journals related to English countries' cultural background. Meanwhile, the cognition of the world and common sense are also important in content schema. So teachers can make a piece of advice to students read broadly so that their content schema can be developed and enriched. 
Third, the construction of formal schema is rooted in teachers' instructing. In reading teaching, teachers may take various types of texts as model essay to let students know different genres and types of texts. Only in this way, can students construct the formal schema well.

\subsection{Schema's Activation}

Schema's activation includes pre-reading activities, while-reading activities and post-reading activities.

\subsubsection{Pre-reading Activities}

Based on schema theory, schema determines readers' comprehension of the text. But sometimes the information that the texts provides are not enough to activate the relevant schema in students' minds. That is, there are cases when students do not store the proper schema. Under such circumstances, teachers can help students activate previous schema or construct related schema through the activities at the pre-reading stage. Question, brainstorming and pre-teaching, pre-texting and pre-discussing are the simple and efficient pre-reading activities.

Question strategically is one of the best methods that can activate students' background knowledge and arouse their interest and curiosity. When preparing for the classes, teachers can combine the text's content and students' knowledge and experience, and then design some efficient questions. Through questioning at the pre-reading stage, teachers can create the active classroom atmosphere and arouse students' reading interest which makes students prone to use their previous knowledge. Whenever teachers or students decide on questions to be answered by reading, they are activating prior knowledge. These questions tend to be able to help the reader focus his attention on the reading material and provide for purposeful reading. Teachers can accomplish this by preparing questions in advance. This will help in guiding readers to a full understanding of their reading assignment.

Brainstorming involves students in a rapid-fire, free-association listing of concepts or ideas or facts or feelings relevant to some topic or context. In these sessions, teachers ask students to examine together the title of the selection they are about to read. The teacher lists on the board all the information that comes to mind as students read the title. These pieces of information are then used to further recall, and in the process considerable knowledge will be activated. creates an atmosphere for students to choose previous background knowledge from brain. This method has two basic steps: the first step is that teachers should make sure the pivotal concept reflecting the the theme of text, and the second step is that list associated words and phrases in a short period. It is a good way to guide students recall and help students know how much the theme knowledge they grasp.

Pre-testing is that before reading students are tested about the known knowledge. Tests can be multiple choice or true or false items. By testing, students are more sensitive to the passage's content so that the comprehension affects knowledge and experience in their minds. This activity requires teachers design several topics before classes for students to discuss in the classes.

\subsubsection{While-reading Activities}

In the pre-reading activities, students' schemata are activated and expanded. While it is possible to activate existing schemata with a given topic, it does not necessarily follow that a student can use this activated knowledge to develop new knowledge and skills. Build on what they already know, students are required to expand on the terms and information they already understand, elicit a large number of associations by the prior knowledge they already possess and make clear connections. Reading under the guidance of teacher and discussing with partners are all effective on-class activities which benefits the development of students' reading abilities.

Reading is an active process and readers are not the passive receivers of text information. So teachers should cultivate students' prediction capability in order to make students experience how the schema plays a predictive part. It does not matter that readers may not predict the details and that what they predict may not in accordance with the text, since it is usually the case. The point is that the prediction can guide them to find the key information and detect the interferential details; therefore, it is very possible that their reading speed can be increased.

It is impossible that any text provides all the details. In many cases, authors make omissions which he or she assume readers understand. More often, authors' intention can only be found between the lines. All this require students develop their ability to infer information from the existed one. To achieve this, class discussion is quite effective. Class discussions and informal talks in and out of class all serve as techniques to discover more about what students bring to their reading. It will facilitate students' oral communication ability in that they will be more active in class discussions. It is best to divide students into several groups so that more students will have more chances to speak in class. Over a period of time, teachers can begin to get some idea as to what their 
students know and can adjust how much time needs to be spent on background information.

\subsubsection{Post-reading Activities}

Schema theory views that the more schema students have, the better students predict. So it is necessary to do the post-reading activities to solidify and enlarge students' schema. Otherwise, the problems students meet in the pre-reading stage and the while-reading stage need to be cleared more after class. There are several effective ways, such as outlining, abbreviation and so on, which are helpful to students' comprehension.

Outlining can help students clear the passage structure and conclude the main idea. It is fundamental to penetrate into the analysis and further discussion of the text.analyzing the passage and discuss. Abbreviation means that students summarize a passage with their own words. This can help student detect those crucial details and the subordinate ones. At the same time they will keep a clear idea about the overall structure of the text. In addition, different types of texts have different organization. Analyzing passage structure of a text can help students predict how the information is developing in the passage. After class discussion is another good way to solve the remaining problems and deepen their comprehension.it can also stir up students' interest of continuing to read other materials of the same or related topic, which surely enhances their schemata. It is also indispensable to do the traditional vocabulary exercise because it is important for the freshman and the sophomore to expand linguistic schemata as well.

\section{Conclusion}

Schema theory refers to the capability of combining one's own background knowledge with the information in a text. It can also be described as a mental structure of pre-conceived ideas, a framework representing some aspect of the world, or a system of organizing and perceiving new information. In this process, the past knowledge and knowledge structure play a crucial role in people's cognitive activities. Schemata influence attention and the absorption of new knowledge: people are more likely to notice things that fit into their schema, while re-interpreting contradictions to the schema as exceptions or distorting them to fit. People use schemata to organize current knowledge and provide a framework for future understanding. The application of schema theory to college English reading teaching facilitates to cultivate students' reading interest, quicken their reading speed and make proper judgments. It can also help students fulfill their task more successfully and have an important impact on English reading teaching. College English reading teaching in schema theory is a heatedly discussed topic. This paper just makes an external study of it. There should be more studies carried out in order to explore the practical strategies.

\section{References}

An, F. C. (2011). Schema Theory and Language Comprehension. Journal of Language and Literature Studies, 2, 4-7.

Bartlett, F. C. (1932). Remembering: A Study in Experimental and Social Psychology. Cambridge: Cambridge University Press.

Carrell, P. L., \& J. C. Eisterhold. (1983). Schema Theory and ESL reading Pedagogy. TESOL Quarterly, 19, 81-92.

Carrell, P. L. (1984). Evidence of a formal schema in second language comprehension. Language Learning and Communication, 2, 87-112. http://dx.doi.org/10.1111/j.1467-1770.1984.tb01005.x

Carrell, P. L. (1988). Some causes of text-boundedness and schema interference in ESL reading. In Carrell, P. L., J. Devine, \& D. E. Eskey (eds.), Interactive Approaches to Second Language Reading. Cambridge: Cambridge University Press.

Cui, Y. P. (2002). Application of Schema Theory in Reading Comprehension. Foreign Language Education, 5, 52-57.

Eskey, D. E., \& W. Grabe. (1988). Interactive models for second language reading: perspectives on instruction. In Carrell, P. L. et al. (eds.), Interactive Approaches to Second Language Reading. Cambridge: Cambridge University Press.

Eskey, D. E. (1988). Holding in the Bottom: An Interactive Approach to the Language Problems of Second Language Readers. Cambridge: Cambridge University Press. pp. 93-111.

Goodman, K. (1988). Interactive Approaches to Second Language Reading. Cambridge: Cambridge University Press. pp. 42-45. 
Heilman, A. W., Blair, T. R., \& Ruply, W. H. (1990). Principles and practices of teaching reading. London: Merrill Publishing Company. p. 117.

Kramsch, C. (1993). Content and Culture in Language Teaching. Oxford: Oxford University Press. pp. 43-51.

Rumelhart, D. E. (1977). Toward an Interactive Mode of Reading. In Dornic (ed), Attention and Performance IV, 6, 573-601.

Rumelhart, D. E. (1980). Schemata: the building blocks of cognition. In R. J. Spiro, B. C. Bruce, \& W. F. Brewer (eds), Theoretical Issues in Reading Comprehension. Hillsdale, New Jersey: Lawrence Erlbaum Associations. pp. 77-85.

Rumelhart, D. E. (1985). Toward an Interactive Model of Reading. Newark, DE: International Reading Association. p. 47.

Shu D. F., \& Ding Z. X. (2002). Modern Foreign Language Teaching. Shanghai: Shanghai Foreign Language Education Press. pp. 44-47.

Zhao Y. F. (2000). An Introduction to Cognitive Linguistics. Shanghai: Shanghai Foreign Language Education Press. pp. 22-34. 